\title{
Los tres exámenes de Luis Violante como maestro carrocero (México, 1803): ¿inepto o extraordinario?
}

\section{Luis Violante's three Exams as a Master Coachbuilder (Mexico, I803): ¿Inept or Extraordinary?}

Artículo recibido el 5 de agosto de 2020; devuelto para revisión el 9 de octubre de 2020; aceptado el 25 de febrero de 202I; https://doi.org/IO.2220I/iie.I8703062e.202I.II9.2759

Álvaro Recio Mir Universidad de Sevilla, alvarorecio@us.es, https://orcid.org/oooo-oooI$7874-5625$.

Líneas de investigación El arte español e hispanoamericano de la Edad Moderna, particularmente el coche de caballos, entendido como obra de arte total y como símbolo de estatus social.

Lines of research Spanish and Hispano-American art of the Modern Age, particularly horse-drawn carriages, understood as total works of art and as a symbol of social status.

Publicación más relevante El arte de la carrocería en Nueva España. El gremio de la Ciudad de México, sus ordenanzas y la trascendencia social del coche (Madrid: Consejo Superior de Investigaciones Científicas-Universidad de Sevilla-Diputación de Sevilla, 2018).

Resumen Un pleito entablado en 1803 en la Audiencia de México contra el carrocero Luis Violante permite conocer el contenido de los exámenes para alcanzar la maestría en dicho arte, que el referido realizó en tres ocasiones. Junto a ello, se trata la cuestión de la recusación de los veedores por parte de los candidatos a dichas pruebas por causas de enemistad y la polémica que ello generaba. Además, hay que sumar otras cuestiones que permiten analizar la situación de dicho gremio al final del virreinato, en particular de quienes eran sus integrantes, y la especialización creciente en el arte carrocero.

Palabras clave Luis Violante; examen; gremio; carrocería; Ciudad de México; Nueva España; 1803.

Abstract A lawsuit brought in I803 before the High Court (Audiencia de México) against the coach builder Luis Violante yields information regarding the contents of exams for attaining the degree of mastery in the 
craft, which Violante sat three times. It also tells of the recusal of the inspectors by candidates to the said tests on the grounds of malice, and the controversies generated thereby. It also raises other questions that need to be taken into account in any analysis of the guild's situation as the Viceroyalty came to a close. These include the matter of who its members were and the increasing specialization in the coachbuilder's art.

Keywords Luis Violante; examinations; guild; coachbuilding; Mexico City; New Spain; 1803 . 
DOI: https://doi.org/10.22201/iie.18703062e.2021.119.2759

\author{
ÁLVARO RECIO MIR \\ UNIVERSIDAD DE SEVILLA
}

\title{
Los tres exámenes de Luis Violante como maestro carrocero (México, I803): ¿inepto o extraordinario?
}

$\mathrm{D}$ e los carroceros novohispanos sabemos aún poco más que sus nombres, con la excepción de Joaquín de Castro, carrocero del virrey Revillagigedo en la última década del siglo Xvin y cuya figura comienza a desentrañarse. ${ }^{I}$ Vinculado profesionalmente a él estuvo Luis Violante, de quien en esta ocasión me ocuparé a partir de su accidentado acceso a la maestría en tal arte.

La fuente será el pleito que contra él entabló, el 3 de noviembre de 1803 y en la Real Audiencia de México, el veedor del gremio de carroceros de la capital virreinal, José Hipólito Ramírez, con la doble intención de que se declarara nulo el examen por el que había alcanzado la maestría y de que se le impidiera el ejercicio profesional. ${ }^{2}$

La prosa procesal que este asunto generó es, en esta ocasión, particularmente expresiva y en ella se entrelazan diversos aspectos que permiten profundizar

I. Álvaro Recio Mir, El arte de la carrocería en Nueva España. El gremio de la Ciudad de México, sus ordenanzas y la trascendencia social del coche (Madrid: Consejo Superior de Investigaciones Científicas-Universidad de Sevilla-Diputación de Sevilla, 2018), 259-26I. Sobre Castro tenemos un artículo en prensa que avanza en su conocimiento respecto a la obra anterior.

2. Archivo General de la Nación de México (en adelante AGN), Instituciones coloniales, Real Audiencia, Civil (023), Civil (volúmenes), contenedor 02I4, vol. 434, exp. 4. 


\section{DOI: https://doi.org/10.22201/iie.18703062e.2021.119.2759}

I44

ÁLVARO RECIO MIR

nuestros conocimientos sobre el ámbito gremial al final de su historia, ya en franca descomposición y al borde mismo de su extinción, como el propio virreinato. Las cuestiones en las que más incide esta fuente son el contenido de los exámenes de maestría y la recusación de los maestros veedores por causa de enemistad. En relación con ello y aun con otros aspectos menores se evidencia el fuerte carácter consuetudinario de buena parte de las prácticas gremiales, más allá del tenor de sus propias ordenanzas, lo cual, además de ocasionar frecuentes disputas, hace difícil desentrañar la práctica de este sistema de producción, de lo que en adelante profundizaré con relación a los carroceros novohispanos de principios del siglo XIX.

\section{El primer examen fallido y la recusación de Ramírez}

El oficial Luis Severino Violante se examinó para acceder a la maestría en primera instancia con el veedor del gremio de carroceros de la Ciudad de México, José Hipólito Ramírez. Éste narró, en el marco del referido pleito, que la prueba se desarrolló en su carrocería, ubicada en la calle de San Pedro y San Pablo de la capital virreinal, estando presentes José Roldan, José Ortiz, Juan Simón Cordero, Francisco Carrizosa y José Morales, todos ellos maestros del arte de la carrocería, a los que les mostró "una rueda chica de coche para que la reconociesen si tenía algún defecto y estaba arreglada". Para dicho reconocimiento cada uno de los referidos maestros "cojió la vara y regla y compás y empezaron a echar sus medidas y a tomar todos los tamaños de dicha rueda". Tras ello, "todos unánimes y conformes, expresaron y dixeron que dicha rueda estaba defectuosa, por no estar arreglada y que los rayos no estaban parejos y [estaban] flojos y que para que quedara algo sujetable era necesario echarlos nuevos". Ramírez informó a los maestros que dicha rueda la había hecho Luis Violante, "que intentaba examinarse de dicho oficio de carrocero". ${ }^{3}$

Se alude, en primer lugar, a una cuestión fundamental de los gremios como era el contenido del examen de maestría. En tal sentido, el punto sexto de las primeras ordenanzas de carroceros de la Ciudad de México de 1706 decía que el oficial en el examen habría de "dar entera noticia de todo aquello de lo se le

3. AGN, Instituciones coloniales, Real Audiencia, Civil (023), Civil (volúmenes), contenedor O2I4, vol. 434, exp. 4, f. 296. 
preguntare, assí en la demostración como en la ejecución”, ${ }^{4}$ lo que contemplaba aspectos teóricos y prácticos.

No obstante, por aquellas fechas y en el marco de la Ilustración, se discutió acaloradamente acerca del contenido de tales exámenes, sobre si tenían que ser de carácter teórico, práctico o combinar ambos aspectos. Esto salió a relucir cuando el fiscal Ambrosio de Sagarzurieta quiso reformar los gremios novohispanos, siguiendo el modelo establecido en la metrópoli por Pedro Martínez de Campomanes. Sus propuestas fueron puntualizadas por el asesor general Rafael Bachiller, todo ello muy poco después del pleito que aquí se aborda, en concreto, en I805. El referido Bachiller afirmó que en el examen para conseguir la maestría de carrocería no era necesario:

executar por si mismo las piezas que le señalaren los veedores, sino que baste saber dibujarlas con las medidas y proporciones correspondientes y dirigir y mandar su execución para que salgan ajustadas a ellas y por el contrario no baste para la aprobación saber hacer dichas piezas sino se figurarlas en dibujo con las medidas y proporciones correspondientes.

Además, proponía que fuese la Academia de Bellas Artes de San Carlos la que certificara a los carroceros la requerida formación en el arte del dibujo. ${ }^{5}$

Por el contrario, el ejemplo de Violante indica que en el caso de los carroceros el examen era en ese momento de carácter práctico y consistía, más que en hacer un coche completo, lo que hubiese sido costoso y complejo, en realizar sólo alguna pieza del mismo, como la referida rueda, que pusiera en evidencia la destreza del candidato. No obstante, el desarrollo del proceso apunta la existencia de exámenes de mayor contenido teórico.

En el referido proceso de 1803, Ramírez recordaba que, conforme a las ordenanzas, "qualquier oficial que pretenda examinarse debe ir antes a trabajar algunos días en los obradores de los veedores y es para que estos reconozcan en lo práctico y material su aptitud, pues en el acto del examen solo se pregunta y responde categóricamente dando idea de las obras con el dibujo", lo que en parte contradice lo que acababa de afirmar. En cualquier caso, seguía diciendo

4. Álvaro Recio Mir, "Un nuevo arte en movimiento para la ostentación social: los primeros coches novohispanos y las ordenanzas del gremio de carroceros de la Ciudad de México de 1706", Anales del Instituto de Investigaciones Estéticas XXXIV, núm. IоI (2012), I3-38.

5. Recio Mir, El arte de la carrocería en Nueva España, 237 y 238. 


\section{DOI: https://doi.org/10.22201/iie.18703062e.2021.119.2759}

que de tal realidad se deducía "que los veedores son los que han de examinarlos", como ocurría en todos los gremios "y es indispensable en el de carroceros, por que siempre han sido aquellos los que lo ha certificado y no otros maestros nombrados al arbitrio". ${ }^{6}$

Las ordenanzas entonces vigentes eran las de 1773 , que habían sido retocadas en 1785 y ampliadas en I800. Realmente, en tal normativa no se especifica nada acerca del contenido del examen, por lo que habría que retrotraerse, como se acaba de indicar, a las primeras ordenanzas de 1706, en las que, además de lo ya visto, su apartado tercero especificaba que quien quisiese examinarse de maestro habría de poder demostrar su formación "con escriptura". Quien no tuviera tal certificación de su formación en el arte de la carrocería habría, en efecto, de trabajar algún tiempo en el taller de un veedor. ${ }^{7}$ Esta última cuestión y cuánto era algún tiempo volvería a salir a relucir en el proceso, igual que la responsabilidad de los veedores de llevar a cabo los exámenes, lo que tampoco se especificaba en las ordenanzas.

Violante, a pesar de ser reprobado en su primer examen, perseveró en su intención de alcanzar la maestría. Para ello, lo primero que hizo fue recusar al veedor Ramírez como examinador ante el juez de gremios, que nombró a otro maestro para tal función. El recusado protestó de esa "nunca vista novedad" y por ser despojado de sus prerrogativas, lo que ocasionaría "al público inexplicables daños". El ofendido Ramírez apostilló que "un hombre que está inepto cometerá los mayores desaciertos en perjuicio y dańo del público", por lo que, al carecer, según él, absolutamente de pericia el candidato, "llamó a cinco maestros para que viesen cómo aquella pieza que se encomendó a el oficial Violante estaba defectuossísima”, de lo que había dado cumplida cuenta. ${ }^{8}$

En su demoledora crítica a Violante, Ramírez seguía diciendo que "es inepto y con desprecio de mi parte, sin la menor constancia de que hubiera

6. AGN, Instituciones coloniales, Real Audiencia, Civil (o23), Civil (volúmenes), contenedor 02I4, vol. 434, expediente 4, ff. 297 y 297 vto.

7. Recio Mir, "Un nuevo arte en movimiento", 17-34.

8. AGN, Instituciones coloniales, Real Audiencia, Civil (023), Civil (volúmenes), contenedor 02I4, vol. 434, exp. 4, f. 297 vto. El argumento del bien público se utilizaba en este tipo de litigios, tan habituales en la Nueva España, como se verá en adelante, al igual que ocurría en otras latitudes, como en el virreinato de Perú. Sonia Pérez Toledo, Los hijos del trabajo. Los artesanos de la Ciudad de México, 1780-1853 (Ciudad de México: El Colegio de México, 1996), 63 y Francisco Quiroz, Gremios, razas y libertad de industria. Lima colonial (Lima: Universidad Mayor de San Marcos, 1995), 33-42. 
cumplido con la ordenanza, ha ido al juez de gremios y lo han examinado otros maestros que ignoraban todo lo acaesido y solo le hasían en lo teórico algunas preguntas", aunque veremos que ello no fue así. Ante todo lo anterior, Ramírez contradecía el "despojo violento en sus facultades de veedor", ya que "los veedores siempre o de inmemorial tiempo han sido [los] que han hecho los exámenes y no otros maestros", hasta que "quince días hace hubo novedad de que, sin contar con ellos, se examinó a don José Girón y ahora seis o siete a don Luis Violante". Por todo ello pedía que se restituyera a los veedores y que no se diera el título de maestro a este último. ${ }^{9}$

En realidad, las ordenanzas de los carroceros novohispanos sólo apuntaban de forma muy indirecta que los veedores tenían la función de examinadores. Así, el punto duodécimo de la referida norma de 1706 les encomendaba que "tengan cuidado que cuando alguno se examinase se den los seis pesos que siempre ha sido costumbre dar para el culto del Santo Ángel”. ${ }^{10}$ Lo cual insiste en la fuerza de la costumbre en el ámbito gremial.

Violante se defendió con vehemencia de las acusaciones de Ramírez, al que se refirió como "segundo veedor del gremio" y del que dijo que, resentido por su recusación y "por la enemistad que le profesa", había acudido a la Audiencia, "pretendiendo con sofísticas cavilosidadas anular su examen". Especificaba que Ramírez había huido "de la jurisdicción ordinaria, que reside para las primeras instancias de estos autos en el presidente y vocales de la junta de gremios y que intenta distraer con estas fruslerías la bien ocupada atención" de la Audiencia. Incluso, afirmaba que intentaba "conseguir sus siniestras miras sin que se oiga a mi parte de cuyo perjuicio se trata". ${ }^{\text {II }}$

Para complicar un poco más las cosas, se sumaba así la delicada cuestión de las competencias jurisdiccionales, ya que para Violente el caso debía ser sustanciado ante el juez de gremios y no en la Audiencia. Ello podría inducir a pensar que Ramírez contaba también con la animadversión de otros sectores gremiales, en particular, con el referido juez de gremios.

En cualquier caso, sobre la referida recusación de Violante a Ramírez giró buena parte del proceso, lo que indica la enorme importancia que este tema tenía, a pesar de que es una cuestión apenas analizada en el marco del

9. AGN, Instituciones coloniales, Real Audiencia, Civil (023), Civil (volúmenes), contenedor O2I4, vol. 434, exp. 4, ff. 298-30I vto.

IO. Recio Mir, "Un nuevo arte en movimiento para la ostentación social”, I3-38.

II. AGN, Instituciones coloniales, Real Audiencia, Civil (O23), Civil (volúmenes), contenedor O2I4, vol. 434, exp. 4, ff. 304 y 304 vto. 


\section{DOI: https://doi.org/10.22201/iie.18703062e.2021.119.2759}

I48

ÁLVARO RECIO MIR

sistema gremial. En el desarrollo del pleito y a instancias de Ramírez, se interrogó a varios profesionales al respecto, a los que también se les pidió su opinión sobre Violante. El primero de los interrogados fue Juan Simón Cordero, que decía "ser español, avecindado en esta corte, maestro de carrocero, de cincuenta años de edad". Afirmaba que hacía 3I años que se examinó de maestro carrocero

y de entonces acá no sabe ni ha visto que ninguno otro haya sido examinado para maestro del mismo oficio sino por los veedores del gremio, cuia costumbre sabe también que ha sido antiquísima, sin que se haya interrumpido hasta pocos días hace que el maestro Aranda y el maestro Carrizosa examinaron a don José Girón, de los cuales Carrizosa no es actual veedor, que también se examinó don Luis Violante por el mismo Aranda y don Antonio Banineli, el qual no es maestro examinado. ${ }^{12}$

Esto pone en evidencia, como también se verá en las siguientes declaraciones, que lo habitual era que los exámenes los llevaran a cabo los dos veedores, aunque esto tampoco se especificara en las ordenanzas.

En segundo lugar, declaró el maestro Francisco Carrizosa, de 56 años, también español y natural y vecino de México. Señaló que siempre han sido los veedores los examinadores, menos

quando le han puesto algún óbice a uno de los veedores, pues en ese caso el juez de gremios elixe a otro de los que han sido veedores para que sea examinador en lugar del acusado, como acaba de suceder con don José Xirón, a quien examinó el declarante de orden del mismo juez de gremios, en lugar de don Ypólito Ramírez,

que como vemos no sólo había sido recusado por Violante. No obstante, entrando en franca contradicción, Carrizosa afirmaba que la recusación de Ramírez había sido una novedad, ya que incluso "quando alguno de los veedores ha estado preso y se ha ofrecido examen, lo han sacado de la captura para el efecto". En cuanto al segundo examen de Violante, aunque reconoció no haber asistido a él, "sabe que lo sinodaron el actual veedor don Juan de Aranda

I2. AGN, Instituciones coloniales, Real Audiencia, Civil (023), Civil (volúmenes), contenedor O2I4, vol. 434, exp. 4, ff. 305 y 305 vto. 
y don Antonio Banineli, que aunque no es maestro examinado, ni puede ser veedor por dicha razón, está matriculado y es diputado del gremio". Al preguntar sobre la pericia de Violante, indicaba que "lo que puede decir es que aunque no lo ha visto trabajando, sabe se ha mantenido de oficial de caxista en carrocerías públicas". ${ }^{13}$

Varias son las cuestiones que cabe destacar de esta declaración; la primera, la cada vez más compleja estructura gremial. En tal sentido, menciona a Antonio Banineli, quien intervino en el segundo examen de Violante y que era diputado del gremio sin ni siquiera ser maestro carrocero, a pesar de que llegaría a alcanzar cierto protagonismo en la carrocería mexicana de la primera década del siglo. ${ }^{\mathrm{I}}$

Por otra parte, la referencia a la calidad de cajista de Violante evidencia una especialización del arte de la carrocería, que desde finales del siglo XVIII vivía una considerable evolución técnica en la que, por ejemplo, adquirieron una gran importancia los herreros, encargados de realizar las cada vez más numerosas piezas metálicas con las que contaran los coches. ${ }^{\text {Is }}$ Es claro que la especialidad de cajista, de la que es ésta la primera referencia con la que contamos, pero de la que veremos otras más adelante, se ocuparía de realizar la caja de los coches, y de igual modo se verá que se apuntaba otra especialidad referida a los trenes de los carruajes. De hecho, la carrocería aglutinaba a numerosas actividades que incluían a herreros, tapiceros, doradores, pintores, guarnicioneros, vidrieros y hasta 15 profesiones distintas. ${ }^{16}$ Un lustro después de este pleito, en una propuesta de nuevas ordenanzas para el gremio de carroceros redactadas por Joaquín de Castro, precisamente con Violante, se hacía incluso alusión a los "individuos que se emplean en el gremio con el nombre de talladores", en evidente alusión a los escultores. ${ }^{17}$

Declaró, en tercer lugar, el maestro Francisco Morales, de 30 años, español, natural y vecino de México, que vino a decir lo mismo que los anteriores. Por su parte, José Manuel Pastrana, de 23 años, también español, natural y vecino

I3. AGN, Instituciones coloniales, Real Audiencia, Civil (O23), Civil (volúmenes), contenedor 02I4, vol. 434, exp. 4, ff. 305 vto y 306.

I4. A este respecto véase Ramón María Serrera, Tráfico terrestre y red vial en las Indias españolas (Madrid: Dirección General de Tráfico, 1993), 332.

15. Recio Mir, El arte de la carrocería en Nueva España, I68-I84.

I6. Jorge González Angulo Aguirre, Artesanado y ciudad a finales del siglo XVIII (Ciudad de México: Fondo de Cultura Económica, 1983), 6r.

17. Recio Mir, El arte de la carrocería en Nueva España, 256. 


\section{DOI: https://doi.org/10.22201/iie.18703062e.2021.119.2759}

I 50

de México, era oficial en el taller de Ramírez, lo que le dio la oportunidad de presenciar el primer examen de Violante, sobre el que dijo que la citada rueda "la hechó a perder". En quinto lugar, José Ignacio Ortiz, de 39 años, espańol, natural y vecino de México, "dixo que en doce años que lleva de maestro examinado no tiene exemplar de que alguno haya sido examinado en su oficio más que por los veedores". El sexto testigo, el maestro Ignacio Gutiérrez, de 33 años, español, natural y vecino de México, sobre la rueda de Violante aseguraba que "ni un muchacho aprendiz la hubiera hecho tan errada". Por su parte, el maestro José Nicolás Rivadeneira, de 53 años, y como los anteriores español, natural y vecino de México, afirmó que la falta de un veedor era sustituida por algún maestro de los más antiguos, "mas nunca ha nombrado a su arbitrio el juez de gremios otro sinodal". En cuanto a Violante, dijo que la rueda la "executó tan mal que la dejó inservible". El octavo testigo, Laureano Pedroso, "español, natural y vecino de esta corte, maestro carrocero de 27 años, no sabe que se haya verificado examen más que por los veedores, solo Xirón y Violante" no siguieron esa norma. De este último dijo que era carrocero, "pero que no desempeñó el acto en que trabajó en la casa de dicho don Ypólito Ramírez, lo que piensa seria por venganza”. Por último, el oficial José María Gallegos, de 30 años, asimismo español, natural y vecino de México, dijo de Violante que "su instrucción no era suficiente para armar un juego de un coche", lo que no pudo firmar por no saber..$^{18}$

Salen a relucir, así, buena parte de los maestros y oficiales de carrocería de México a principios del siglo xix. Destaca el carácter de españoles de todos ellos. Es ésta una cuestión discutida, ya que Castro Gutiérrez ha afirmado que las ordenanzas de los carroceros sólo permitían el ejercicio profesional a los españoles. A ello se aludía en un interesante parecer del procurador general del ayuntamiento recogido por dicho historiador, que en relación con los carroceros decía:

pocos gremios tienen esa calidad de que sólo espańoles limpios aprendan el oficio, algunos más tienen la calidad de limpieza para ser maestros del oficio y otros solo requieren la limpieza para ser veedores y en otros indistintamente se admiten para veedores de cualquier color y calidad. Algunos gremios han querido poner esta misma ordenanza de que sólo españoles puedan aprender el oficio y se ha

I8. AGN, Instituciones coloniales, Real Audiencia, Civil (023), Civil (volúmenes), contenedor O2I4, vol. 434, exp.4, ff. 306 vto-310 vto. 
rechazado y con razón, porque hay muchos mulatos en el reino y estos se han de ocupar en algo. ${ }^{19}$

No obstante, las ordenanzas de 1773 especificaban que "el que hubiere de examinarse de maestro, antes ha de dar información de ser español, yndio, mestizo o castizo limpio de mala sangre y casta y sin esta calidad justificada no pueda ser admitido a examen ni obtener el título de maestro". Por su parte, el referido proyecto de ordenanzas de 1807 , de Joaquín de Castro, dejaba en manos de la autoridad la cuestión de la limpieza de sangre, aunque indicaba que los carroceros habían procurado siempre que sus miembros fueran de sangre limpia. ${ }^{20}$

Por otra parte, en las referidas declaraciones se vuelve a criticar al juez de gremios, ya que sus autores afirmaban que la sustitución de los veedores en caso de recusación se había hecho tradicionalmente por el gremio. Sin duda, esta intervención del referido juez no era más que otro signo del creciente control de la administración sobre los gremios tan propio de este momento y auspiciado por las reformas ilustradas. Por otro lado, en una nueva contradicción, todos los declarantes valoraban la labor de Violante de manera despectiva, incluso los oficiales, como si tuvieran la calidad de examinadores, lo que evidencia que eran testigos bien seleccionados por Ramírez.

Violante, por su parte, presentó otros testigos para que fuesen interrogados acerca de si la recusación era práctica corriente y si también era habitual en los demás gremios de México. En tal sentido, el maestro carrocero Juan José Aranda declaró que "siempre ha sido y es costumbre poder recusar a los veedores de qualquier gremio quando las partes tienen motivo de resentimiento". Por su parte, Antonio Banineli vino a decir lo mismo, igual que Miguel Gallardo, José Ignacio Roldán y Francisco Carrizosa. Además de los anteriores carroceros, José Calapis Matos, secretario mayor del Cabildo, especificó que la recusación era siempre factible, aun en el caso de que el que la solicitase no pudiese "sufragar los gastos que exige la instrucción de un expediente formal circunstanciado". ${ }^{21}$

19. Felipe Castro Gutiérrez, La extinción de la artesanía gremial (Ciudad de México: Universidad Nacional Autónoma de México, 1986), 95 y 98. En esta misma obra, en las tablas sobre gremios que incluye, se evidencia la presencia de criollos y mulatos entre los carroceros.

20. Recio Mir, El arte de la carrocería en Nueva España, II6, 257 y 258.

2I. AGN, Instituciones coloniales, Real Audiencia, Civil (023), Civil (volúmenes), contenedor O2I4, vol. 434, exp. 4, ff. 329-33I vto. 


\section{DOI: https://doi.org/10.22201/iie.18703062e.2021.119.2759}

I 52

Aunque las declaraciones de los testigos de Violante no son tan precisas como las de los de Ramírez, cabe destacar que entre unos y otros sumaban al menos una docena de maestros y unos pocos oficiales, de manera que por el pleito de 1803 pasó buena parte de la profesión. De particular importancia es el número de maestros, sobre todo teniendo en cuenta que a finales del siglo XVIII se registra sólo un número algo mayor de ellos, ${ }^{22}$ lo que prueba que este litigio tuvo un alcance enorme en el seno de la carrocería.

El referido José Calapis Matos daba también algunos datos sobre la historia de la carrocería novohispana que merecen ser recogidos. Dijo al respecto que en 1773 "solicitó examinarse de carrocero Mariano Ramírez, para lo que recusó al veedor Agustín Sánchez de Vargas, que habiéndolo la mesa de propios por recusado le mandó acompañase con otro maestro como lo efectuó con los que se le señalaron". Otro caso similar se produjo en I762, cuando "recusó don Antonio Roldán a don Pablo Ortiz, veedor del gremio de carroceros al que también se hubo por recusado y se le acompañó con el maestro más antiguo". Por último, Calapis Matos decía que "en el presente año solicitó examinarse de carrocero don José Xirón, quien recusó al veedor del gremio al que se hubo por recusado y se nombró a uno de los veedores antepasados”. ${ }^{23}$

En cualquier caso, ya apunté que la recusación no es una cuestión estudiada en el ámbito gremial. En tal sentido, el clásico estudio sobre los gremios novohispanos de Carrera Stampa sólo dice que era una cuestión habitual en el marco gremial y que se sustanciaba tanto en el Cabildo, como en la Audiencia y demás tribunales. ${ }^{24}$ No obstante, las declaraciones que antes he recogido nos informan que, si bien no era ni mucho menos habitual, tampoco la que aquí se estudia fue un hito único. Como vengo señalando, el problema, además de los enfrentamientos personales que las ocasionaban, radicaba en que era una

22. Recio Mir, El arte de la carrocería en Nueva España, I63.

23. También alude a recusaciones en otros gremios, así en 1764 "recusó José Godoy al alcalde y veedor del gremio de tintoreros, los que se hubieron por recusados en el todo y aunque sobre ello interpusieron recurso en esta real audiencia su alteza en auto de trece de julio se sirvió confirmar la determinación de la mesa de propios con pena cincuenta pesos a los veedores si molestasen al recusante". Otro ejemplo de i8or era el de "don Juan Manuel de Valderraín para su examen en el novilísimo arte de primeras letras recusó al maestro mayor don Rafael Ximeno al que se hubo por recusado y se mando que los veedores por si solos procediesen al examen como lo excusaron". AGN, Instituciones coloniales, Real Audiencia, Civil (023), Civil (volúmenes), contenedor 0214, vol. 434, exp. 4, ff. 332-332 vto.

24. Manuel Carrera Stampa, Los gremios mexicanos: la organización gremial de Nueva España, I52I-I86I (Ciudad de México: Cámara Nacional de la Industria de Transformaciones, I954), 62. 
cuestión no recogida en las ordenanzas de carroceros, por lo que se había de acudir a la costumbre para su regulación, lo cual siempre era más discutible que una norma escrita.

En el marco del asunto de la recusación, Ramírez insistió en su queja "por haver nombrado nuevos examinadores el juez de gremios para que procediesen al examen del referido Violante" y pidió "que no se le recogiese el titulo que se le dio", ni que pudiese ejercer la profesión. Fundamentaba negarle el título en que "no podía satisfacer ni executar las preguntas que se le hicieron". De igual modo, afirmaba que "sería muy perjudicial al gremio el que los examinados al ver que no podían dar completa satisfacción se valiesen del arbitrio de ocurrir al juez para que por medio del favor". Por otra parte, argumentaba que:

un capítulo de la ordenanza previene que el que se hubiese de examinar del dicho oficio haya de dar entera noticia y satisfacción de todo aquello que le fuere preguntado, así en la demostración como en la execución, y otro que al carrocero toca hacer coches, forlones, sillas volantes, literas y todo aquello que mira a andar en animales quadrúpedos.

En relación con ello, afirmaba que "Violante está tan distante de saber esas operaciones que ni aún supo poner [...] unos rayos, cuya operación es capaz de hacer el aprendiz más moderno". También decía "que la ordenanza previene que el que se haya de examinar trabaje algún tiempo en casa de los maestros veedores cuyo hecho no se ha verificado". Por último, apuntaba asimismo que "no todos pueden examinar, sino aquellos que tiene facultad por la misma ordenanza [...] de suerte que es presiso sean maestros examinados con el titulo de veedores para aprobar o reprobar al esaminado". ${ }^{25}$

La machacona insistencia de Ramírez tenía razón en que las ordenanzas, en concreto, las de 1706, decían que "[al oficio de] carrocero toca hacer coches forlones, sillas volantes, literas y todo aquello que mira a andar en animales cuadrúpedos". La misma norma alude también, como vimos al contenido del examen. Por otra parte, Ramírez mostraba el habitual sentido elitista gremial con relación a la profesión al afirmar que no todos los oficiales podían aspirar a ser maestros, y reiteraba una vez más que sólo los veedores podrán examinarlos.

25. AGN, Instituciones coloniales, Real Audiencia, Civil (O23), Civil (volúmenes), contenedor O2I4, vol. 434, exp. 4, ff. 3II-3I3 vto. 


\section{DOI: https://doi.org/10.22201/iie.18703062e.2021.119.2759}

I 54

ÁlVARO RECIO MIR

Resulta excepcional que el propio Violante relate vívidamente el contenido de su primer examen, por lo que merece citarse en su integridad:

pasé la mañana del día veinte y cinco del que corre [octubre de 1803] a la casa del segundo veedor, don Juan José Aranda, para que me examinara, quien lo executó en lo que toca al exercicio y práctica de encino o juegos de coches, la tarde del mismo día pasé con el mismo objeto a casa del primer veedor don Hipólito Ramírez, el que, de luego a luego, me presentó la misma especie de examen que había sufrido en la mañana, ocupando en él toda la tarde. ${ }^{26}$

Ante tal reiteración en el contenido de las pruebas propuestas Violante afirmaba que:

es costumbre y aún está establecido en semejantes exámenes que los veedores hagan distintas preguntas o hagan al examinante que manifieste su instrucción en diversos ramos que se compone su arte para dar entero cumplimiento a la ordenanza y que manifiesten su aprovechamiento. Don Hipólito Ramírez, sin embargo, que sabía que don Juan José Aranda me había examinado de dicho exercicio de juegos, no me tocó el de cajas, que no es menos importante que el primero, tanto por la seguridad con que deben construirse como para manifestar su hermosura y buena disposición. Los motivos que haya tenido don Hipólito para no haverme echo distinto examen que el primero no lo sé, pero si me persuadió que haya sido con solo el objeto de molestarme, entretenerme y aprovecharse de mi trabajo, pues no quedando satisfecho con toda la tarde que trabajé me citó para que después continuase. Una sola hora es suficiente para que qualesquiera inteligente en su arte pueda hacerse cargo de que otro lo sea o que carece de las luzes que son necesarias para él. Ni la razón, ni la equidad, ni la justicia toleran el que uno con las manos limpias (como suele decirse) se aproveche del trabajo de otro, como quiere don Hipólito hacerlo conmigo, valiéndose de la autoridad que piensa tener sobre los que como yo nos tenemos que sujetar a su aprobación, por todo lo expuesto a vuestra merced suplico se sirva mandar el que el veedor don Hipólito Ramírez se abstenga de semejantes excesos y tenerlo por recusado como recuso en toda forma con el juramento de la ley dejándolo en su buena opinión y fama. ${ }^{27}$

26. AGN, Instituciones coloniales, Real Audiencia, Civil (023), Civil (volúmenes), contenedor O2I4, vol. 434, exp. 4 , ff. 316 .

27. AGN, Instituciones coloniales, Real Audiencia, Civil (O23), Civil (volúmenes), contenedor O2I4, vol. 434, exp. 4, ff. 316-317. 
No obstante, la expresiva justificación de Violante para la recusación nos parece débil e incluso cabría calificarla de infantil, ya que vimos que los examinadores podían plantear cuantas cuestiones quisieran discrecionalmente. De igual modo, su referencia a que en una hora se puede discernir la capacidad de un candidato no parece demasiado consistente ni fundamentada, sobre todo en un arte tan complejo como el de la carrocería.

En cualquier caso, resulta del máximo interés la alusión de Violante, en el desarrollo de su queja, a los distintos ramos con los que contaba el arte de la carrocería. En relación con la ya referida especialización en la manufactura de coches, cobran sentido sus palabras, las cuales parecen indicar que hubo al menos una distinción básica entre los juegos o trenes de los carruajes y sus cajas. Seguramente más técnica la primera cuestión, ambas estaban vinculadas a la carpintería, aunque la primera, tanto por lo que se refiere a los ejes de las ruedas como a la suspensión del carruaje, estaría más relacionada con la herrería que las cajas.

Tras la anterior discusión, la recusación de Violante a Ramírez fue admitida y el juez de gremios en su lugar nombró "al veedor don José Roldán para que en consorcio del actual veedor don Juan José Aranda procedan al examen”. ${ }^{28}$ Roldán había sido con anterioridad veedor y ya lo vimos con relación al primer examen de Violante, ya que fue uno de los cinco maestros a los que Ramírez les mostró la tan criticada rueda por la que el primer examen fue reprobado.

\section{El segundo y tan aprobado como cuestionado examen}

Del segundo examen de carrocero al que se sometió Violante, el escribano mayor de cabildo dijo que, fue:

la tarde del día de ayer veinte y ocho [de octubre de I803] a la calle Real, a la casa de don Rafael Sornoza para presenciar el examen que se debía hacer para titularse de maestro carrocero el oficial don Luis Violante. Encontré en ella a el primer veedor del gremio, don Juan José Aranda, y a los diputados don Antonio Banineli y don Miguel Gallardo, con el indicado oficial, esperando únicamente al veedor pasado don José Roldán, nombrado para el efecto por el señor juez por recusación del segundo veedor Hipólito Ramírez y como se demorase se le mandó primero y

28. AGN, Instituciones coloniales, Real Audiencia, Civil (O23), Civil (volúmenes), contenedor O2I4, vol. 434, exp. 4, f. 317 . 


\section{DOI: https://doi.org/10.22201/iie.18703062e.2021.119.2759}

156

ÁLVARO RECIO MIR

segundo recado, que no se le dio por no haverse encontrado hasta la tercera vez, que pasando el presente escribano a la de su morada le encontré en la calle y haviéndole reconvenido por qué no había concurrido a el examen, dixo que con motivo de haver visto en casa de Hipólito Ramírez una rueda mal echa de coche, que le dijo el mismo Ramírez la havía echo don Luis Violante, no podía en conciencia concurrir a dicho examen sin que primero fuera a su obrador el indicado oficial a travajar en todo lo que le pareciere conducente del arte, para satisfacerse por sí mismo y en su virtud poder con esta material experiencia aprobarlo o reprobarlo y que por lo mismo no había concurrido [y] no pensaba hacerlo hasta tanto que cumpliese el indicado oficial con la calidad referida, como se lo había dicho al mismo señor juez, con quien estaba de acuerdo en el particular, por haverle dicho que no solo era costumbre sino también de justicia. ${ }^{29}$

A pesar de la incomparecencia de Roldán, Aranda y los referidos diputados examinaron a Violante, prolijamente especificaron, para así poderlo después aprobar o reprobar. ${ }^{30}$

El 29 de octubre, el juez de gremios, a tenor de la petición de Roldán, dictó que Violante fuese:

a trabajar a su casa en todas las cosas del arte que juzgue necesarias para satisfacerse plenamente de su pericia y en su consequencia poderlo aprobar o reprobar $[\ldots]$ con asistencia del primer veedor, don Juan Aranda, diputados y la del presente escribano, a fin de que en su virtud pongan por diligencia lo que resultase.

Esto fue notificado a Violante, el cual afirmó "que no solo estaba pronto a pasar a trabajar a la casa del maestro Roldán para satisfacerlo de su aptitud, sino también a todas las de otros maestros más que tubiere por conveniente el señor juez, como no sea a la de Hipólito Ramírez" . ${ }^{\text {I }}$

De esta forma, Violante llegó al taller de Roldán, "como a las nuebe de la mañana, en compañía del primer veedor, don Juan de Aranda, y el diputado don Miguel Gallardo" y, tras saludarse,

29. AGN, Instituciones coloniales, Real Audiencia, Civil (O23), Civil (volúmenes), contenedor O2I4, vol. 434, exp. 4, ff. 317 vto-318 vto.

30. AGN, Instituciones coloniales, Real Audiencia, Civil (023), Civil (volúmenes), contenedor 02I4, vol. 434, exp. 4, ff. 318 vto.

3I. AGN, Instituciones coloniales, Real Audiencia, Civil (O23), Civil (volúmenes), contenedor O2I4, vol. 434, exp. 4, ff. 3I8 vto-319 vto. 
dio principio el maestro Roldán a examinar a el expresado oficial por una maza de rueda torneada que executó puntualmente en presencia de todos, con todas las dimensiones y arreglos necesarios, luego le mandó dicho maestro a el indicado oficial que la taladrara con arreglo a el arte, que también lo executó del mismo modo, habiendo tomado el compaz el maestro sinodal para reconocerla y después de encontrarla exacta, dixo que estaba arreglada y buena y siendo ya como las doze y media del día, dixo el maestro Roldán que estaba satisfecho en todas sus partes de las operaciones del oficial por que quien había executado esta en todas sus dimensiones con la perfección que lo hizo estaba en aptitud de ser maestro y que por tal lo daba y tenía.

Insistía el referido Roldán en que "le había satisfecho enteramente", por lo que "lo daba y juraba por tal maestro en el referido arte respecto de su aptitud en la parte que le toca según su leal saber y entender". ${ }^{2}$

En cuanto al contenido de esta segunda parte del examen, se insiste en que Violante "torneó una rueda, escopleó y taladró", ${ }^{33}$ lo que apura aún más su contenido. De este modo, se alude a las técnicas de tornear, escoplear y taladrar, así como a las herramientas con las que se hacían, torno, escoplo y taladro, sobre lo que volveré más adelante. Por su parte, la referida maza es el bloque cilíndrico que constituye el centro de la rueda, en el que se introduce el eje sobre el que debe de girar y en el que se insertan los rayos o radios de la misma. ${ }^{34}$

Igual juramento que Roldán hizo Aranda, el cual afirmó haber encontrado a Violante apto en el arte de carrocería, no sólo "en la construcción de caxas, ruedas y demás según sus medidas tamaños y proporciones respectivas que le preguntó y executó materialmente según el plano que exive y pone de manifiesto para que se agregue, sino también en otras varias cosas menores del mismo arte". ${ }^{35}$

Se insiste así en la distinción ya referida entre trenes o juegos y cajas, a lo que en este caso se ańade la alusión a otras cosas menores, lo que no hace más que poner en evidencia que la construcción de carruajes era un arte de suma

32. AGN, Instituciones coloniales, Real Audiencia, Civil (023), Civil (volúmenes), contenedor O2I4, vol. 434, exp. 4, ff. 319 vto-320.

33. AGN, Instituciones coloniales, Real Audiencia, Civil (o23), Civil (volúmenes), contenedor O2I4, vol. 434, exp. 4, ff. 326 vto.

34. Luis Rivero Merry, Manual de enganches (Sevilla: Caja Rural, I986), 37.

35. AGN, Instituciones coloniales, Real Audiencia, Civil (o23), Civil (volúmenes), contenedor O2I4, vol. 434, exp. 4, f. 320 vto. 


\section{DOI: https://doi.org/10.22201/iie.18703062e.2021.119.2759}

158

ÁlVARO RECIO MIR

complejidad. De igual modo, resulta muy expresiva la alusión al plano, que suponemos relativa al diseño de los coches, asunto que se discutía también en ese momento en relación con los exámenes de los maestros carroceros novohispanos como ya apunté. Todo parece indicar que Violante hizo tanto el plano como la ejecución material de lo representado en él.

De este modo, el 5 de noviembre de 1803 , la junta de gremios, por "el examen que rigorosamente se le hizo al oficial de carrocero don Luis Severino Violante para titularse de maestro del mismo arte con que se le ha dado cuenta desde luego las aprobaban y aprobaron $[. .$.$] y en su concequencia mandaban$ y mandaron que, acreditando el citado Violante haver enterado los derechos de media annata se le libre por el oficio el titulo correspondiente", lo cual se le notificó al interesado el 7 de noviembre. ${ }^{36}$

\section{El tercer, triunfal y también discutido reconocimiento o examen y la definitiva expedición del título de maestro carrocero}

A pesar de haber aprobado su segundo examen, Violante fue informado de que "el citado veedor Ramírez, resentido de la recusación, se ha puesto en movimiento, dando a entender que yo tengo poca aptitud para el exercicio a mayor abundamiento del rigoroso examen que he sufrido y para mi satisfacción en quanto concierne a dejar ilesa en esta parte mi suficiencia en la maestría, sin que sirva de exemplar a otro yndividuo", pedía al juez que:

antes de expedirme el titulo, se nombre dos maestros del oficio de carrocero, quales sean los que merezcan toda la confianza de este tribunal, para que por una especie de reconocimiento, sin qualidad de examen, declaren bajo de juramento si en el caso de ser ellos actuales veedores pondrían algún embargo para que se me confiriera el título, cuya diligencia se practique por ante el presente escribano mayor de cabildo que autorizó el examen, quien igualmente certifique lo que por su parte advierta, tanto en la teoría como en la práctica con referencia a lo que igualmente precenció en el primer acto. ${ }^{37}$

36. AGN, Instituciones coloniales, Real Audiencia, Civil (023), Civil (volúmenes), contenedor O2I4, vol. 434, exp. 4, ff. 32I vto y 322.

37. AGN, Instituciones coloniales, Real Audiencia, Civil (O23), Civil (volúmenes), contenedor O2I4, vol. 434, exp. 4, ff. 322-323. 
De este modo, el 7 de noviembre y "sin que sirva de exemplar para lo sucesivo por no haber sido costumbre”, los miembros de la junta de gremios:

nombraban y nombraron a los dos veedores que lo fueron en muchas ocasiones del gremio, don Joaquín de Castro y don Miguel José Guzmán, para que por sí mismos examinen y reconozcan la aptitud o ineptitud de esta parte en dicho exercicio y por consiguiente puedan jurar sobre ella según y conforme pide en su escrito, asistiendo el escribano mayor de cabildo a estas diligencias para que pueda certificar lo que en ellas ocurra como lo hará de las anteriores. ${ }^{38}$

La llamativa velocidad de todo el proceso hizo que el mismo día del anterior acuerdo,

procedió el maestro don Joaquín de Castro como más antiguo a examinarle y dando principio tomó una tabla que estaba allí azepillada y limpia (desde luego, para otro fin) y poniéndola sobre un banco de los de donde trabajan le pidió trazara en una rueda delantera, su cambija de costado y frente, su despunte de rayos con su copado correspondiente, escopleadura y cuñero de la maza, concluidas estas operaciones tomó el maestro examinador lo executado en la mano y registrándolo muy por menor dixo a el otro maestro procediese a pedir lo que le pareciese.

Por su parte, el otro examinador, Guzmán,

pidió le formase de un trozo de fresno bruto y labrase un pilar de caxa de coche antiguo redondo a la española de dos escarsanas primera y segunda, lo que executó del mismo modo que con el primero y siendo reconocido por los dos mancomunadamente dixeron havía cumplido exactamente con lo que se le había pedido y como que era la una del día y haber estado manifestando su aptitud desde las nueve de la mańana, lo declaraban y declararon apto y capaz para poder ser maestro.

Además, ambos maestros pidieron que "les permitiesen poner su firma en la tabla y pilar para su constancia y no pulsando embarazo accedí a que lo executaran como en efecto lo hicieron". ${ }^{39}$

38. AGN, Instituciones coloniales, Real Audiencia, Civil (023), Civil (volúmenes), contenedor O2I4, vol. 434, exp. 4, ff. 323 y 323 vto.

39. AGN, Instituciones coloniales, Real Audiencia, Civil (o23), Civil (volúmenes), contenedor 02I4, vol. 434, exp. 4, ff. 324 y 324 vto. 


\section{DOI: https://doi.org/10.22201/iie.18703062e.2021.119.2759}

160

ÁLVARO RECIO MIR

Se da la circunstancia de que este tercer y extraordinario examen es del que con más especificidad conocemos su contenido, particularmente técnico. En tal sentido, lo que le propuso Castro fue que "trazara en una rueda delantera, su cambija de costado y frente, su despunte de rayos con su copado correspondiente, escopleadura y cuñero de la maza”, es decir, que dibujara una rueda delantera, cuestión que como ya vimos también salió a relucir en el primer examen. No obstante, es difícil descifrar en detalle el contenido de este tercer examen, que contó tanto con el dibujo como con la ejecución material de las piezas, ya que se empleó un lenguaje que evidencia la enorme especificidad técnica que había alcanzado el sofisticado arte de la carrocería. El único tratado de carrocería en lengua castellana, el Tratado del coche de Antonio de Torres, fechado en Madrid en 1796 y que quedó manuscrito, contiene un utilísimo diccionario que nos puede ser de alguna ayuda al respecto, al igual que el Diccionario de autoridades. Este último dice de la referida cambija, voz no mencionada por Torres, que es un término de alarifes que alude a la línea recta y ángulos rectos. Los rayos, en la actualidad llamados radios, se definen en el Tratado como "los palos de encina casi redondos o bien labrados en forma de lomo de águila que se fixan por una parte en los cubos y por otra en las pinas de las ruedas del coche, uniendo y trabando de este modo los mismos rayos, la circunferencia y el centro de las mismas ruedas". En cuanto al término cuñero, Torres dice que las cuñas son "piezas pequeñas, tableadas de madera y disimuladas en sus puntas que se meten a golpe de mazo o de martillo entre las escopleaduras y las espigas de algunas piezas de madera del carro y de la caxa del coche para que subsistan firmes y unidas y no resulte entre ellas la menor separación". ${ }^{40}$ Por su parte, el término maza ya lo definimos.

Las ruedas, lógicamente, fueron elementos fundamentales de los coches de caballos y de hecho tenemos referencia de que hubo profesionales especializados en su manufactura e incluso, algo después del momento que nos ocupa, avanzado el siglo XIX, algunas fábricas se especializaron en la realización de las mismas para los carruajes, particularmente en los Estados Unidos de América, desde donde se abasteció a todo el mundo. ${ }^{41}$ A principios del siglo XIX,

40. Diccionario de la lengua castellana en que se explica el verdadero sentido de las voces... (Madrid: Francisco del Hierro, I726-1739), ad vocem y Biblioteca Nacional de Espańa (en adelante BNE), MSS/I055O; Antonio de Torres, Tratado del coche y cálculo prudente de los bienes y males que produce... y un discurso sobre la necesidad del exercicio... y un diccionario de los nombres de todas sus piezas, ad vocem.

4I. Recio Mir, El arte de la carrocería en Nueva España, I73. 
tras el triunfo del modelo carrocero inglés, el tipo más habitual de rueda fue la llamada "dished wheel", que no era plana ya que su cubo o maza caía ligeramente hacia adentro, lo que le da cierta concavidad. El exterior de la rueda solía estar recubierto por una llanta de hierro, mientras que su circunferencia estaba realizada con trozos curvos de madera ensamblados y llamados pinas. Los rayos o radios solían ser una docena para las ruedas delanteras, cuyo diámetro era la mitad que el de las traseras, las cuales contaban con 14 rayos. Todos estos radios convergían y se insertaban en la referida maza, que se barrenaba o escopleaba, como se ha dicho con anterioridad, en su centro para dejar sitio al eje..$^{42}$

Por su parte, Guzmán le pidió a Violante que hiciera un "pilar de caxa de coche antiguo redondo a la española de dos escarsanas primera y segunda". Torres define los "pilares de la caxa" como "los quatro listones fuertes perfinados que salen de los quatro ángulos del suelo de la caxa y cruzan el bastidor del texadillo entre cuyas piezas tan principales y las manijas se establece toda la formación de la misma caxa del coche". ${ }^{43}$ La referencia a las escarzanas y a que el coche era de caja redonda invita a pensar que el referido pilar era también curvo. El coche aludido apunta, además de a la obvia influencia española en la carrocería novohispana, al recuerdo de la carrocería barroca, aunque sabemos que ya a principios del siglo xIx habían triunfado en las calles de México los sobrios carruajes de filiación inglesa, de volúmenes básicamente rectos. ${ }^{44}$

Violante justificó este nuevo examen "no por que fuese necesario", ya que se hallaba "plenamente examinado y aprobado", sino para "plena identidad y satisfacción de esta junta de los veedores y diputados que lo sinodaron y lo que es más, del mismo interesado, para poderse titular de maestro con más pleno conocimiento para el efecto de su aptitud, de que no hay exemplar hasta el presente desde la erección del gremio". Entendía su caso como algo único y que no sería en adelante modelo por lo costoso y nocivo que resultaría a los artesanos la práctica de iguales diligencias. En cualquier caso, los miembros de la junta de gremios "mandaban y mandaron se le expida el titulo correspondiente". 45

Los dos examinadores, los maestros Castro y Guzmán, "conociendo su sobresaliente habilidad, pedían se les permitiere que las maderas trabajadas se condujesen a el oficio del cabildo para que se conservasen y que además se

42. Isabel Turmo, "Construcción de carruajes", Reales sitios, núm. I3 (1969): 33-40.

43. BNE, MSs/Ios5o, De Torres, Tratado del coche.

44. Recio Mir, El arte de la carrocería en Nueva España, 245-304.

45. AGN, Instituciones coloniales, Real Audiencia, Civil (O23), Civil (volúmenes), contenedor O2I4, vol. 434, exp. 4, ff. 324 vto-325 vto. 


\section{DOI: https://doi.org/10.22201/iie.18703062e.2021.119.2759}

I62

ÁLVARO RECIO MIR

les concediese la satisfacción de poner su firma en todo lo conducente al despacho del examen de este individuo", ${ }^{46}$ lo que evidencia el referido carácter práctico del examen y la excepcionalidad de los resultados del mismo, que así se convirtieron en modélicos.

No obstante, los examinadores del segundo examen mostraron sus recelos a esta tercera e inusual prueba. Así, Juan José Aranda, José Roldán, Antonio Banineli y Miguel Gallardo declararon haber ya examinado a Violante, el cual había respondido "con mayor eficacia de la que ordinariamente se acostumbra respecto a otros", destacando su "superabundante actitud y pericia" y certificando haberlo aprobado. También indicaban que habían sabido que se le había examinado de nuevo, lo que

no solo es nosivo al gremio del que somos las cabezas principales por los costos y perjuicios que pueden interferirle a los individuos que quieran examinarse en lo sucesivo, sino que a mayor abundamiento lo es a nosotros mismos, por el agrabio que en ello conceptuamos se ha inferido en nuestro honor y reputación y lo que es más en la posesión inmemorial que tenemos de sinodar a los que hayan de titularse de maestros en nuestra facultad o exercicio, aprobándolos o reprobándolos según la mayor o menor aptitud del pretendiente, pues aun quando se recuse alguno de los sinodales, siempre se nombra en su lugar otro de los veedores pasados, sin que por este echo nunca haya avido la novedad que notamos en nombrar distintos sinodales para nuevo sínodo, como se ha hecho ahora sin que por lo mismo podamos presindir de usar de los derechos que en esta parte tenemos que representar. ${ }^{47}$

A la postre, Juan José Aranda, primer veedor; José Roldán, veedor pasado; Antonio Banineli y Miguel Gallardo, primero y segundo diputados del gremio, declararon que, tras reconocer el expediente sobre tercer examen de Violante,

que se le ha hecho por los maestros veedores del año pasado don Joaquín de Castro y don Miguel José Guzmán ha sido por formal pedimento del mismo don Luis Violante para acreditar con extraordinaria superabundancia su mayor capacidad y aptitud en el arte, como lo hizo plenamente con asistencia del escribano mayor de

46. AGN, Instituciones coloniales, Real Audiencia, Civil (023), Civil (volúmenes), contenedor O2I4, vol. 434, exp. 4, ff. 325 vto-326 vto.

47. AGN, Instituciones coloniales, Real Audiencia, Civil (O23), Civil (volúmenes), contenedor O2I4, vol. 434, exp. 4, ff. 327-328 vto. 
cabildo... no solo con el fin de satisfacerse a sí mismo, a vuestra señoría y a nosotros según así está en su escrito de siete del corriente.

Es decir, aunque lo aceptaban, advertían que no "sirva de exemplar para lo sucesivo", ya que sería "nosivo y costoso esta práctica a los pobres artesanos"..$^{8}$

El que no aceptó este tercer examen fue Ramírez, quien el 24 diciembre de I803, en una larga argumentación arremetió de nuevo contra Violante, afirmando que "todo el bien y felicidad común de las repúblicas depende del aumento y progreso de las artes, por eso en las bien ordenadas y dirigidas se han erigido en gremios". A ello añadía que "la sociedad toda se intereza en que los artefactos estén bien construidos y acondicionados y en que los que dibujan las obras respectivas a sus oficios sean idóneos, expertos y capaces de ello. Esta qualidad tan interesante y más necesaria en el oficio de carrocero que en las demás, nunca la ha poseído ni la pose en el día el oficial Violante, a pesar de havérsele expedido el titulo vicioso y colorado de maestro". ${ }^{49}$

La crítica de Ramírez a Violante seguía diciendo que tenía "unos conocimientos sobradísimos de su ineptitud" y que "es incapás de ser maestro carrocero". Aludía de nuevo a la rueda del primer examen, que él y sus testigos dijeron que era inservible, por ello ponía en duda el segundo examen, del que dijo que hubiese debido tener "una más prolija y exacta averiguación", sobre todo si "no es capaz de armar una rueda, siendo esto tan fácil y sensillo". Del contenido del tercer examen dijo que "no prueba la instrucción que se debe apetecer en un maestro", especificando que "la del pilar de caxa, que fue práctica, prueba quando mucho que Violante es caxista, no carrocero". De este último examen afirmaba también que en él Violante "no arguye conocimientos prácticos del oficio" y que se hizo en su casa. ${ }^{\circ}$

Insistía así en la ya referida distinción, que en este caso se hace ya explícita, entre cajista y carrocero. De igual modo, aludía Ramírez al tercer examen que se hizo en casa de Violante, lo que pone en evidencia que ejercía ya como carrocero. Resulta sorprendente que la contravención de este principio básico del ámbito gremial no fuera más insistentemente aducida por Ramírez en el pleito.

48. AGN, Instituciones coloniales, Real Audiencia, Civil (O23), Civil (volúmenes), contenedor O2I4, vol. 434, exp. 4, ff. 332 vto-333.

49. AGN, Instituciones coloniales, Real Audiencia, Civil (o23), Civil (volúmenes), contenedor O2I4, vol. 434, exp. 4 , ff. 40 vto y 34 I.

50. AGN, Instituciones coloniales, Real Audiencia, Civil (O23), Civil (volúmenes), contenedor O2I4, vol. 434, exp. 4, ff. 34I vto-343. 


\section{DOI: https://doi.org/10.22201/iie.18703062e.2021.119.2759}

I64

ÁLVARO RECIO MIR

La larga alegación de Ramírez recordaba que las ordenanzas señalaban que el oficio ha de ser "aprendido con escriptura y los que no la tengan hayan de trabajar por algún tiempo a casa de los maestros veedores". Afirmaba que Violante no había cumplido con ello, ya que, aunque había ido a la casa de Ramírez y Aranda, ese tiempo "no debe ser instantáneo, sino duradero y capás de subsanar la falta de escriptura”. Repetía que quienes tenían que juzgarlo eran los veedores, lo que anulaba las pruebas de Violante. Volvía al asunto de recusación, que calificaba de temeraria y contraria a lo que dicen las ordenanzas, ya que "no se procedió como devía ser". Para lograr el favor del juez, decía también que "los veedores tienen por las ordenanzas fundada su intención para examinar, al modo que los juezes ordinarios la tiene por derecho". Insistía en que hacían falta causas legítimas para dicha recusación, mientras que la de Violante era "porque la materia del examen fue sobre juego de coche, en la que había sido ya examinado por el otro veedor", cuando los veedores tenían libertad para preguntar lo que quisieran, de lo que deducía que la de Violante fue una recusación maliciosa. Del mismo modo, añadía a su dispar batería de disconformidades que el juez de gremios no tiene autoridad para remover a un veedor y poner otro en su lugar, ya que "la elección de veedor es privativa de todos los maestros según las ordenanzas" y protestaba una vez más por haber sido despojado de sus derechos en tal sentido. Terminaba su larguísima declaración afirmando que Violante tiene "menos instrucción en el oficio que aun aprendiz de él", por lo que insistía en la nulidad de su examen. ${ }^{\text {II }}$

Ante esta nueva intervención de Ramírez, se volvió a citar a Violante, del que el I4 de enero de I804 dijo el receptor que "no habiendo encontrado en la carrocería del puente de los Gallos a don Luis Violante, le entregué el papel prevenido a un oficial que dixo nombrarse Miguel Violante y ser hermano de aquel, con especial orden de que se lo diera en mano propia para su inteligencia”. El 3I de enero Violante reiteraba que Ramírez "no intenta otra cosa que impedir y dilatar el curso del negocio para que no llegue a descubrirse su temeridad"..$^{22}$

El 2I de marzo de 1804 Violante pidió que se le restituyese el uso y ejercicio de su oficio y que fuese condenado en costas Ramírez. Insistía en la "prueba más de bulto del odio y encono que Ramírez profesa a mi parte por

5I. AGN, Instituciones coloniales, Real Audiencia, Civil (O23), Civil (volúmenes), contenedor O2I4, vol. 434, expediente 4, ff. 344-348.

52. AGN, Instituciones coloniales, Real Audiencia, Civil (O23), Civil (volúmenes), contenedor O2I4, vol. 434, exp. 4, ff. 350-35I vto. 
resentimiento cuyo recuerdo no es ahora del caso, que este mismo empeño en litigar, este ardor contradictorio en costear un pleito tan opuesto a la imparcialidad". A pesar de no ser del caso en ese momento, se decía con relación al primer examen que "Violante no creyó que se extendiesen tanto sus malas intenciones e hizo un esfuerzo de confianza para poner en sus manos". Pero

después de haverlo mortificado toda la tarde para que armara una rueda de coche con las camas, maza y rayos [...] le citó para otro día, con ánimo sin duda de quitarle otra mańana sino otros muchos días con el pretexto de cumplir con la ordenanza, según la rara inteligencia que le ha dado, pero con el verdadero objeto de aprovecharse del trabajo de los pobres menestrales que tiene la desgracia de sujetarse a su calificación.

Reiteraba que en el examen Ramírez le hizo una prueba igual a la que acababa de realizar con el otro veedor, lo que probaba "la malignidad de don Ypólito", ya que la carrocería tenía "muchísimos ramos". Confesaba también "que no es un estudiante acostumbrado a actos públicos, sino un pobre rústico que era la primera vez en su vida que exponía a calificación su suficiencia, se llenó de horror al contemplar comprometida toda su suerte fortuna en el arbitrio de un hombre que consideraba mal queriente". Por ello le recusó, y seguía afirmando que "los que entran a examen son generalmente unos infelices que apenas alcanzan para comer con su trabajo". Contradecía en todo a Ramírez en un largo alegato, en el que aludía a su envidia y planteaba incluso con relación a la rueda del primer examen "no siendo imposible que Ramírez la descompusiera a propósito para llevar a delante su capricho", ya que era inverosímil que quien es "diestro en otras operaciones mucho más difíciles de su arte, hechara a perder esta tan fácil y tan sencilla”. En cambio, se ufanaba en proclamar que los otros maestros que le habían evaluado certificaron de él "una perfecta instrucción en la teórica de una rueda de coche". ${ }^{33}$

Por fin, el I6 de enero de I805, el regente y los oidores de la Audiencia Real de la Nueva España ponían fin al proceso al declarar que:

don Luis Violante puede usar del título que se le expidió de maestro carrocero y exercer este oficio a cuyo efecto se levanta la suspensión impuesta en auto de nueve

53. AGN, Instituciones coloniales, Real Audiencia, Civil (O23), Civil (volúmenes), contenedor O2I4, vol. 434, exp. 4, ff. 355-368 vto. 


\section{DOI: https://doi.org/10.22201/iie.18703062e.2021.119.2759}

I66

ÁLVARO RECIO MIR

de noviembre de mil ochocientos tres y se previene a la junta de gremios de esta ciudad observe puntual y exactamente lo que previene las respectivas ordenanzas en quanto a los exercicios y prácticas que deben preceder a los exámenes y a las formalidades con que estos deben hacerse y los sujetos que han de examinarlos. ${ }^{54}$

No se ha conservado el referido título de maestro carrocero, lo que hubiera complementado los datos ofrecidos en el litigio. Sí se conservan otros títulos de maestría, de los cuales es particularmente significativo el del arquitecto Lorenzo Rodríguez, que culminaba un enfrentamiento similar al que en esta ocasión nos ocupa, en este caso entre él y Miguel Custodio Durán. 5

No obstante, a pesar de la riqueza del pleito que ha servido de fuente, silencia importantes cuestiones. Así, nada se dice acerca de quién fue el maestro con el que se formó Violante. Cabría sospechar incluso que fuese el propio Ramírez, lo que podría haber originado la evidente animadversión que se profesaban.

En cualquier caso, todo el proceso deja entrever la vibrante personalidad de Violante, al que imaginamos como un joven impulsivo y orgulloso, ya que alteró las normas gremiales para demostrar su valía profesional. Como en tantas ocasiones ocurre con los litigios profesionales, también éste sería ocasionado por larvadas disputas personales. Sin duda, la reiteración de Ramírez en que, como veedor, le había sido arrebatada injustamente su prerrogativa de examinar a los aspirantes a maestros, así como sus insultos a Violante, también dejan traslucir una personalidad orgullosa y altiva, que a buen seguro chocó de manera enconada con la de Violante. Resulta llamativo que Ramírez arremetiese contra Violante y no contra el referido Girón, que también lo había recusado, lo que podría corroborar la particular animadversión que suponemos. Pienso, por tanto, que este pleito se originó por el enfrentamiento de dos caracteres verdaderamente volcánicos.

54. AGN, Instituciones coloniales, Real Audiencia, Civil (O23), Civil (volúmenes), contenedor O2I4, vol. 434, exp. 4, ff. 37I-372.

55. Manuel Romero de Terreros, "La carta de examen de Lorenzo Rodríguez", Anales de Instituto de Investigaciones Estéticas IV, núm. I5 (1947): I05-I08. Sobre otras cartas de exámenes véase Patricia Díaz Cayeros, "Una carta de examen para obtener el título de maestro del carpintero poblano Pedro", Anales del Instituto de Investigaciones Estéticas XXIV, núm. 8I (2002): I5I-I60; Humberto Triana y Antorveza, "Exámenes, licencias, finanzas y elecciones artesanales", Boletín Cultural y Bibliográfico 9, núm. I (1966): 65-73 y José Antolín Nieto Sánchez, "Gremios artesanos, castas y migraciones en cuatro ciudades coloniales de Latinoamérica", Historia y Sociedad, núm. 35 (2018): I7I-I97. 
También cabría plantearse contestar la pregunta que ha servido de subtítulo y que he tomado del propio proceso: ¿era Violante inepto o extraordinario? Nada concluyente se puede afirmar al respecto, pero el carácter ejemplarizante de lo realizado por él en el tercer examen, así como los elogios vertidos sobre el mismo en el segundo, parecen inclinar la balanza a afirmar que no era un maestro común.

En tal sentido, cabe decir que el desarrollo profesional de Violante, con posterioridad a su examen de maestría, debió de alcanzar alguna significación en la Ciudad de México. A ese respecto, destaca que su nombre estuviese vinculado al de Joaquín de Castro, con relación al referido proyecto de nuevas ordenanzas que éste redactó en 1807 en el marco de la reforma ilustrada de los gremios. ${ }^{56}$ No obstante, apenas sabemos algo más sobre su carrera, al igual que lo que ocurre, como se dijo ya, con la inmensa mayoría de los carroceros novohispanos. Sólo conocemos, como se señaló antes, que su taller se ubicaba en el Puente de los Gallos y que contaba con su hermano Miguel como oficial.

Más allá del caso concreto, cabe abstraer alguna significación sobre el sistema gremial en general. En primer lugar, se mencionó ya el carácter consuetudinario de parte de sus normas, junto a la escasa especificación de sus ordenanzas. Esto enlaza con una evidencia: hubo constantes divergencias entre la realidad y las normas. Las propias normas, más que sucederse las unas a las otras, parece que se acumulaban, como se apuntó en relación con las ordenanzas de los carroceros.

Otra cuestión llamativa es la creciente burocratización del marco gremial. En tal sentido destacan figuras como el juez de gremios, regidor del ayuntamiento, cuya finalidad era que las corporaciones gremiales acataran las normas. ${ }^{57}$ Esto se relacionaba de forma directa con la mayor intervención de la autoridad municipal y judicial en la vida gremial; al respecto son significativas las constantes referencias de Ramírez a que en caso de recusación habría de ser el propio gremio quien nombrase otro veedor y no el juez de gremios, como ocurrió en la ocasión que tratamos.

Otras figuras referidas en el pleito eran los diputados del gremio. En tal sentido, en el proyecto de ordenanzas de Joaquín de Castro de 1807 la jerarquía gremial la formaban un maestro mayor, dos veedores, dos diputados y un tesorero. De los diputados decía Castro que su función sería asociarse

56. Recio Mir, El arte de la carrocería en Nueva España, 245.

57. Pérez Toledo, Los hijos del trabajo, 6I. 
en el gobierno del gremio a los tres primeros "y aiga en quien recaigan a el ańo venidero semejantes empleos", de manera que se aseguraba la sucesión en los cargos. ${ }^{58}$

En cualquier caso, este sistema de producción tocaba a su fin en el momento en que se dan los hechos de los que me he ocupado, ya que por disposición de las cortes de Cádiz los gremios fueron suprimidos legalmente en I8I4, aunque de facto y sin sus tradicionales prerrogativas se prolongaron en el tiempo hasta avanzado el siglo XIX. ${ }^{59}$ Esta proyección temporal pone en evidencia la enorme importancia de seguir investigando la cuestión gremial, lo cual, para el caso de la carrocería, nos ayudará a abordar en un futuro, que esperamos próximo, el estudio de la carrocería del México independiente. \$

58. Recio Mir, El arte de la carrocería en Nueva España, 247.

59. Pérez Toledo, Los hijos del trabajo, 22. 